\title{
Nylon-6/rubber blends: 8 . Influence of the molecular weight of the matrix on the impact behaviour
}

\author{
K. Dijkstra* and R. J. Gaymans† \\ University of Twente, PO Box 217, 7500 AE Enschede, The Netherlands \\ (Received 11 March 1993)
}

\begin{abstract}
Blends of nylon- 6 with polybutadiene were prepared with comparable morphology and different molecular weights of the matrix. These specimens were tested using the notched Izod impact test and the notched tensile impact test. An increase in molecular weight resulted in a shift of the brittle-to-tough transition temperature of $40^{\circ} \mathrm{C}$ to lower temperatures. In the notched tensile impact tests, especially in the high-speed region, pronounced differences between blends with different molecular weights of the matrix were observed.
\end{abstract}

(Keywords: nylon-rubber blend; impact behaviour; molecular-weight effects)

\section{INTRODUCTION}

Until now, the greater part of the research effort when studying nylon/rubber blends was directed towards clarification of the relation between the microstructure (i.e. the morphology) of the blend and its mechanical properties $^{1,2}$. The influence of the mechanical properties of the impact modifier on the impact behaviour ${ }^{3}$ and the function of adhesion between matrix and dispersed phase in the toughening mechanism ${ }^{4}$ have also been treated in the literature.

It has, in fact, proven to be very difficult to study the influence of the matrix properties on the impact behaviour of nylon/rubber blends, since a change in the physical properties of the matrix material will, in most cases, result in a drastic change in blend morphology. When, for example, nylon- 6 is replaced by nylon-6,6, the rubber particles are no longer spherical ${ }^{5,6}$ and the amount of occluded matrix material in the dispersed phase is reported to increase strongly?

An important question is which mechanical properties of the matrix are important for the toughening mechanism. Normally most attention is focused on the elastic moduli and the yield stress. Surprisingly the ultimate properties (fracture stress and fracture strain) of the matrix are often left aside. It can be expected that these properties will play a crucial role in crack initiation and propagation.

For polymers it is well known that in general the fracture stress and fracture strain increase with increasing molecular weight. The Young's modulus and yield stress of commercial nylon-6 types, however, are rather insensitive to molecular weight. This indicates that the crystallinity is also hardly affected by molecular weight. For polyethylene the dependence of fracture stress on molecular weight was explained from the number of tile molecules between the crystalline regions ${ }^{8}$. With

*Current address: DSM Research, PO Box 18,6160 MD Geleen, The Netherlands

† To whom correspondence should be addressed

0032-3861/94/020332-04

(C) 1994 Butterworth-Heinemann Ltd. increasing molecular weight the number of tie molecules increases also, which leads to a higher fracture stress.

To get more insight into the influence of the structural parameters of the matrix in the deformation and fracture behaviour, blends with varying molecular weight and a comparable morphology and rubber type are prepared. In order to by-pass problems in blend preparation that may occur due to the different rheological behaviours of nylons with different molecular weights, the blends are based on a commercial blend that proved to have a very stable morphology over a wide range of extrusion conditions. This master blend was diluted to a lower rubber content with nylon having a very high molecular weight, and with nylon having a very low molecular weight.

It is assumed here that polyamides with different molecular weights will mix homogeneously and will transamidate to give a homogeneous nylon phase. It is known that transamidation of nylons takes place under the extrusion conditions used ${ }^{9,10}$.

\section{EXPERIMENTAL}

\section{Materials}

The master blend used is a commercial nylon6/polybutadiene (type Durethan BC303) obtained from Bayer. The rubber content is about $30 \mathrm{vol} \%$.

The low-molecular-weight type nylon-6 is Akulon $\mathrm{K} 120$, kindly supplied by Akzo; density $\rho=1.14 \mathrm{~g} \mathrm{ml}^{-1}$ and $\eta_{\text {rel }}$ in $96 \% \mathrm{H}_{2} \mathrm{SO}_{4}$ is 2.0 . The high-molecular-weight type nylon-6 is Akulon M258, obtained from Akzo; $\eta_{\mathrm{rel}}=5.8$.

For tests on pure nylon-6 specimens, an injection moulding grade of nylon-6, Akulon K124, obtained from Akzo, is used; $\eta_{\mathrm{rel}}=2.4$.

\section{Blend preparation}

Blending was done on a Berstorff ZE 25 co-rotating twin-screw extruder (screw diameter is $25 \mathrm{~mm}, L / D=33$ ). The master blend and the nylon-6 $(48.2 / 51.8 \mathrm{wt} \%)$ were 


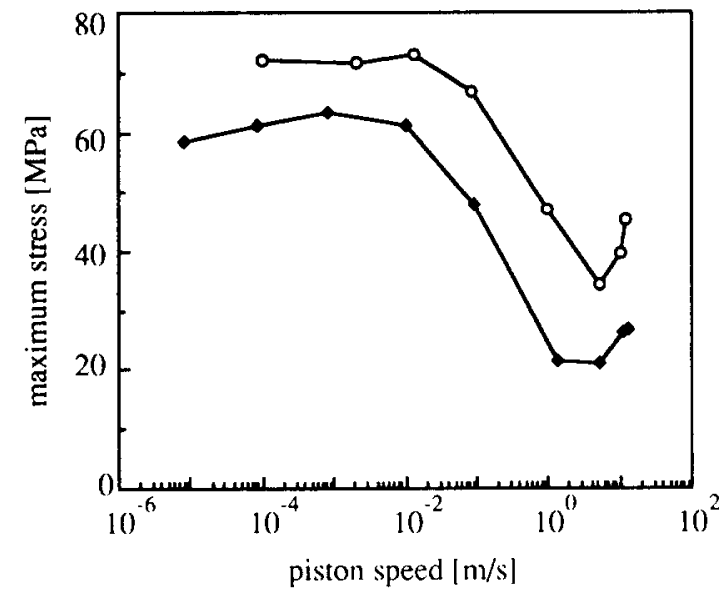

Figure 1 Maximum stress versus piston speed for two unmodified nylons with different molecular weights: $(\bullet) \mathrm{K} 124$, (O) M258

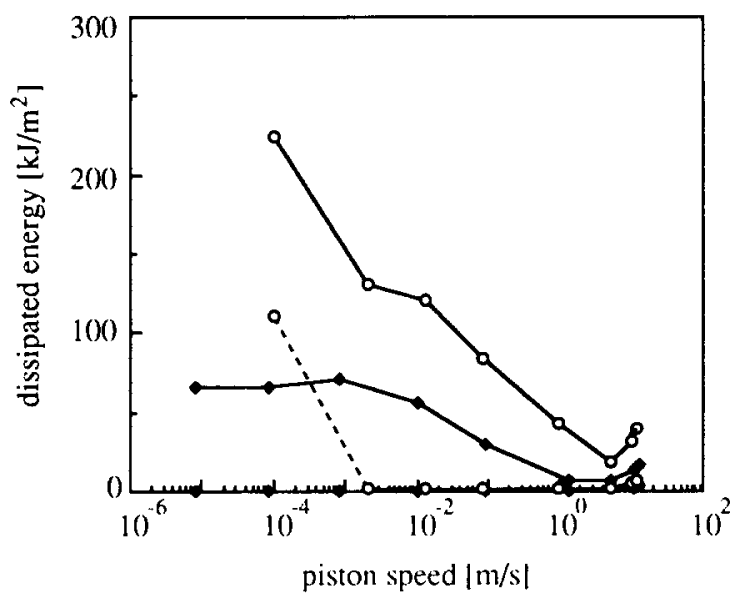

Figure 2 Fracture energy and propagation energy versus piston speed for two unmodified nylons with different molecular weights: $(\diamond)$ K124, (O) M258; ( - - ) fracture energy, (-- ) propagation energy

fed in the first zone with a supply rate of $2 \mathrm{~kg} \mathrm{~h}^{-1}$. The barrel temperature was $260^{\circ} \mathrm{C}$ and the screw speed $100 \mathrm{rev} \mathrm{min}^{-1}$.

Specimens for the mechanical tests (according to ISO 180-1A) were injection moulded on an Arburg Allrounder 221-55-250. The notch was machined in the specimen. Before the mechanical tests, the specimens were dried at $110^{\circ} \mathrm{C}$ under vacuum for $18 \mathrm{~h}$.

For characterization of the blend morphology a sample was taken out of an injection-moulded specimen. On this sample a smooth surface was prepared with a diamond knife on a CryoNova LKB 2285-050 microtome. The sample temperature during microtoming was $-110^{\circ} \mathrm{C}$. From these samples the rubber was extracted from the surface by etching in boiling $m$-xylene for about $12 \mathrm{~h}$. After drying the samples at $110^{\circ} \mathrm{C}$ under vacuum overnight they were covered with a layer of gold and examined with a JEOL JSM-35CF scanning electron microscope. The particle size was determined from the micrographs.

\section{RESULTS AND DISCUSSION}

Influence of molecular weight on the fracture toughness of nylon-6

When unmodified nylons with different molecular weights are tested with the notched Izod, the results are very similar. In all cases, the fracture type changes from brittle to tough when the $T_{\mathrm{g}}$ is passed. When the impact toughness in the brittle region of M258 is compared with that of $\mathrm{K} 124$, it seems that the high-molecular-weight nylon has a somewhat higher impact strength (5 and $3 \mathrm{~kJ} \mathrm{~m}^{-2}$ respectively).

When the two materials are tested with the NTI test, the differences are more pronounced. In Figure $l$ the maximum stress of the two nylons is given. It appears that the stress level for the high- $M_{\mathrm{w}}$ material is somewhat higher and that the transition from semi-brittle to brittle ${ }^{2}$ behaviour has shifted to a higher speed. More striking, however, is that the K124 is brittle over the entire speed range tested (see the propagation energy in Figure 2), whereas the M258 has a transition from brittle to tough behaviour between the piston speeds 1 and $0.1 \mathrm{~mm} \mathrm{~s}^{-1}$. The high- $M_{\mathrm{w}}$ material appears to have a higher fracture energy, also in the semi-brittle and the brittle region. This indicates that an increase in the molecular weight not only increases the fracture energy, but also results in a shift in the brittle-to-tough transition. That this shift is not visible in the notched Izod is probably caused by the fact that the $T_{\mathrm{g}}$ is an upper limit for the brittle-to-tough transition temperature.

\section{Influence of the molecular weight of the matrix on the} fracture energy of nylon/rubber blends

In Table 1 the morphology of the two blends is given. It is clear that diluting the master blends with nylons with different molecular weights has not influenced the blend morphology. Also the homogeneity of the blend was the same for both materials.

In Figures 3 and 4 the results of the NTI tests are given. For the low speeds, the maximum stress of $\mathrm{Mw}-\mathrm{h}$ is slightly higher than that of $\mathrm{Mw}-\mathrm{l}$. This is consistent

Table 1 Blend morphology of the blends with different molecular weights

\begin{tabular}{|c|c|c|c|c|c|c|c|}
\hline \multirow{2}{*}{$\begin{array}{l}\text { Blend } \\
\text { code }\end{array}$} & \multicolumn{3}{|c|}{ Blend composition (wt $\%$ ) } & \multirow{2}{*}{$\begin{array}{l}\text { Rubber } \\
\text { fraction }\end{array}$} & \multirow{2}{*}{$\begin{array}{l}d_{\mathrm{n}} \\
(\mu \mathrm{m})\end{array}$} & \multirow{2}{*}{$\begin{array}{l}d_{\mathrm{w}} \\
(\mu \mathrm{m})\end{array}$} & \multirow[b]{2}{*}{$d_{\mathrm{w}} / d_{\mathrm{r}}$} \\
\hline & $\mathrm{BC} 303$ & $\mathrm{~K} 120$ & M258 & & & & \\
\hline Mw-1 & 48.2 & 51.2 & 0.0 & 0.15 & 0.23 & 0.29 & 1.25 \\
\hline Mw-h & 48.2 & 0.0 & 51.2 & 0.15 & 0.23 & 0.29 & 1.27 \\
\hline
\end{tabular}

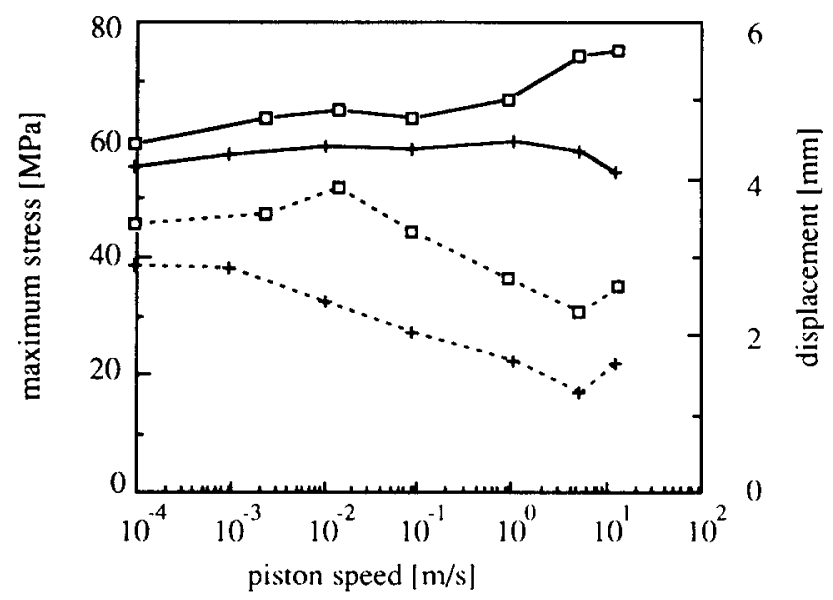

Figure 3 Maximum stress and initiation displacement versus piston speed for the blends given in Table $1:(+) \mathrm{Mw}-\mathrm{l},(\square) \mathrm{Mw}-\mathrm{h}$; $(-)$ maximum stress, $(--)$ initiation displacement 


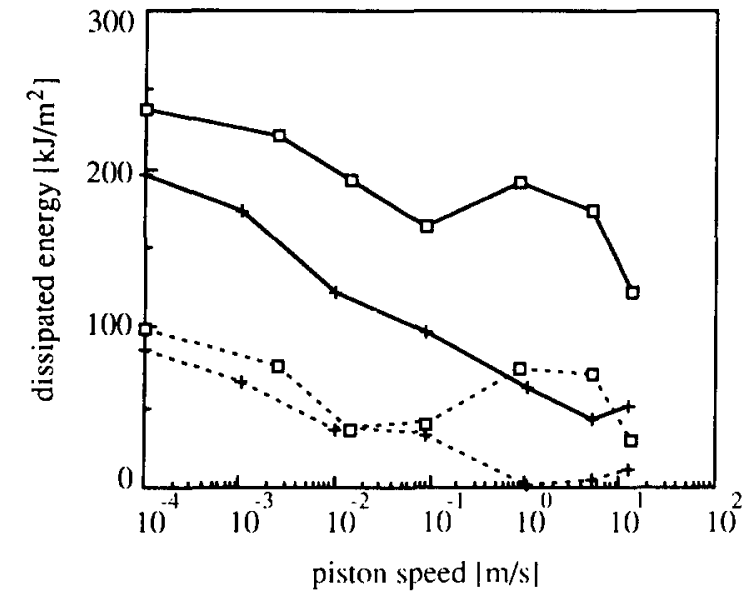

Figure 4 Fracture energy and propagation energy versus piston speed for the blends given in Table $1:(+) \mathrm{Mw}-\mathrm{l},(\square) \mathrm{Mw}-\mathrm{h} ;(\stackrel{-}{\square})$ fracture energy, (-- ) propagation energy

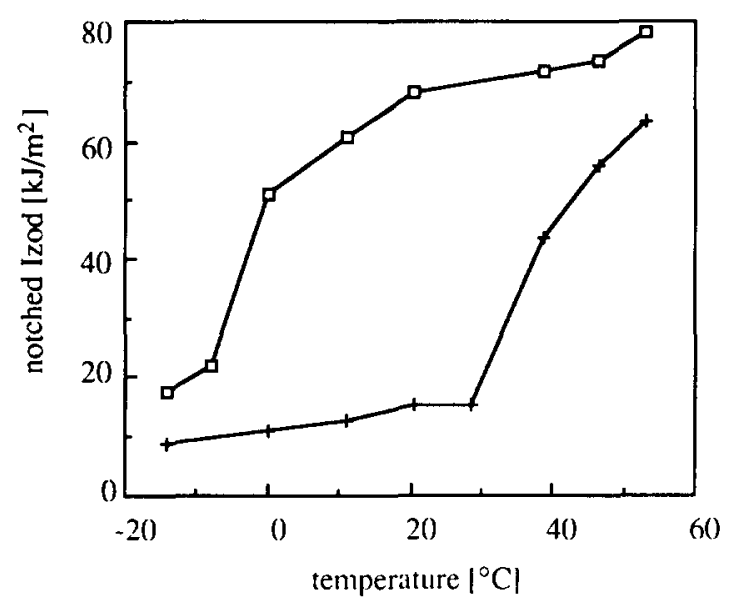

Figure 5 Notched Izod versus temperature for the blends given in Table 1: (+) Mw-1, ( $\square$ ) Mw-h

with the fact that usually the yield stress increases slightly with increasing molecular weight. The fracture energy in this region, however, is considerably higher for Mw-h. This is for the greater part caused by the fact that the clamp displacement to reach the maximum stress (the initiation displacement) is relatively high for $\mathrm{Mw}-\mathrm{h}$. This results in a high initiation energy. The propagation energy is very similar for both materials in the low-speed region.

Mw-l has a transition from tough to brittle between 0.1 and $1 \mathrm{~m} \mathrm{~s}^{-1}$ (see the propagation energy in Figure 4). Mw-h fractures in ductile fashion for almost all test speeds. Only the highest test speed gives a low propagation energy for the $\mathrm{Mw}-\mathrm{h}$ material, although the fractured specimens still showed stress-whitening over the entire fracture surface.

The results of the notched Izod tests (Figure 5) show a shift in the $T_{\mathrm{BT}}$ of about $40^{\circ} \mathrm{C}$ to lower temperatures when the molecular weight of the nylon is increased. This means that the critical interparticle distance also is a function of the molecular weight of the matrix. The fact that the critical interparticle distance increases with increasing molecular weight is an extra indication that the percolation model of Margolina et al. ${ }^{11}$ does not hold. The yield stress of the blend increases slightly with increasing molecular weight. From the viewpoint of the percolation model this should lead to a slight increase of the $T_{\mathrm{BT}}$ and not to a decrease of almost $40^{\circ} \mathrm{C}$.

It is also notable that the results of the NTI tests suggest that the increase in molecular weight results in an increase of about two decades in the draw speed where the fracture type changes from tough to brittle (see the propagation energy in Figure 4). When the temperature-time dependence of the yield stress and the modulus is observed, it should be expected that this corresponds with a shift in temperature of about $10-15^{\circ} \mathrm{C}$. The observed shift in the $T_{\mathrm{BT}}$, however, is much larger. This is in agreement with the fact that with high strain rates the crack growth is believed to be stabilized by the formation of a melt layer around the crack tip. Whether the melt temperature is reached is dependent more on the transition from isothermal to adiabatic deformation than on the temperature interval that has to be overcome.

\section{Relation between fracture stress, yield stress, crack tip} radius and size of the plastic zone

When the plastic zone around a crack tip is discussed, an often used approximation is the firstorder approximation of Irwin ${ }^{12}$, where the stress around the crack tip is limited by the yield stress. With this approximation it was possible to estimate the size of the plastic zone as a function of the stress concentration and the yield stress ${ }^{13}$.

When the material shows strain hardening (as most polymers do), the stress in the plastic zone will not be constant, but will increase with increasing strain (i.e. when approaching the crack tip). In this case the size of the plastic zone will be a function of the stress concentration and of the ratio between yield stress and fracture stress. An important parameter for the amount of stress concentration is the crack tip radius. With decreasing crack tip radius the stress concentration will be stronger. The local fracture stress will be constant; for this reason the applied stress necessary for crack propagation will decrease and also the size of the plastic zone will decrease. A schematic representation of the situation is given in Figure 6.

Which parameters determine the actual size of the crack tip radius does not follow from this analysis. It might be expected that the crack tip radius is determined by a complex interaction of the strain distribution in the plastic zone, the length of the crack and of the specimen dimensions. An analysis of this complexity is, however, beyond the scope of this paper.

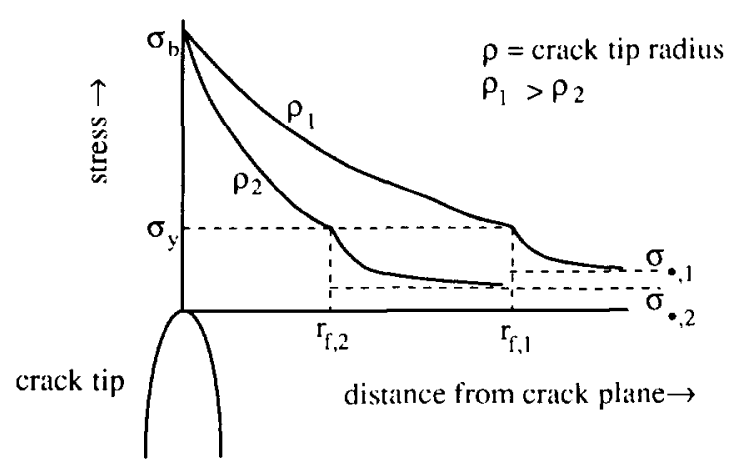

Figure 6 Schematic representation of the stress field around a crack tip in a strain-hardening material for two different crack tip radii; $r_{\mathbf{f}}$ is the size of the plastic zone 
Critical parameters in toughening of nylon- 6

When the results of the NTI tests and the notched Izod tests on unmodified nylon and nylon/rubber blends with different molecular weights of the polyamide are studied, it appears that there are three parameters that determine whether the specimen will fail in brittle or ductile manner.

The fact that unmodified nylon- 6 has a transition in fracture behaviour at the $T_{\text {g }}$ indicates that the modulus is a critical parameter. Yield stress and fracture stress do not change discontinuously when going through $T_{\mathrm{g}}$, but the modulus decreases strongly. A second parameter is the yield stress. The strong difference between nylon and nylon/rubber blends has been explained from the fact that cavitation of the rubber phase resulted in a strong increase in von Mises stress ahead of the notch or crack tip ${ }^{14,15}$. With cavitation the modulus and the fracture stress do not change strongly ${ }^{16}$. Finally, an increase in molecular weight results in an increased fracture stress, while modulus and yield stress stay fairly constant. Therefore, three parameters seem to determine the fracture behaviour: modulus, yield stress and fracture stress.

The importance of yield stress and fracture stress for the size of the plastic zone is demonstrated in this paper. In what way the modulus affects the fracture behaviour is less clear. It is expected that the yield strain increases above $T_{\mathrm{g}}$, which leads to an increase in the size of the plastic zone. A decrease in modulus will also result in a decrease in stored internal elastic energy. Therefore, the elastic energy release will decrease in the case of a low modulus, which can lead to a more ductile behaviour.

\section{CONCLUSIONS}

The molecular weight of the matrix material has a strong influence on the impact behaviour of nylon/rubber blends. Increasing the molecular weight results in a strong decrease of the $T_{\mathrm{BT}}$ measured with the notched Izod and in an increase in the tough-to-brittle transition speed in the NTI test. The latter shift, however, is smaller than might be expected on the basis of the shift in $T_{\mathrm{BT}}$. This is an extra indication that the formation of a melt layer is essential for ductile behaviour at high deformation rates.

The influence of the molecular weight is believed to be caused by the increase in the ratio of fracture stress and yield stress with increasing molecular weight. An increase in this ratio will lead to a larger plastic zone and, for this reason, to tougher behaviour.

\section{ACKNOWLEDGEMENTS}

We would like to thank Prof. Dr. Ir. L. C. E. Struik for helpful discussions. This work is part of the research programme of the University of Twente and was financially supported by the SON/STW.

\section{REFERENCES}

1 Borggreve, R. J. M., Gaymans, R. J., Schuijer, J. and Ingen Housz, J. F. Polymer 1987, 28, 1489

2 Wu, S. Polymer 1985, 26, 1855

3 Borggreve, R. J. M., Gaymans, R. J. and Schuijer, J. Polymer 1989, 30, 71

4 Borggreve, R. J. M. and Gaymans, R. J. Polymer 1989, 30, 63

5 Oshinski, A. J., Keskkula, H. and Paul, D. R. Polymer 1992, 33, 268

6 Oshinski, A. J., Keskkula, H. and Paul, D. R. Polymer 1992, 33, 284

7 Ban, L. L., Doyle, M. J., Disko, M. M. and Smith, G. R. Polym. Commun. 1988, 29, 163

8 Huang, Y. L. and Brown, N. J. Mater. Sci. 1988, 23, 3648

9 Bresler, S. E., Korshak, V. V., Pavlova, S. and Finogenov, P. A. C. R. Acad. Sci. USSR 1954, 87, 961

10 Gaymans, R. J. and Sikkema, D. J. in 'Comprehensive Polymer Science' (Eds. G. Allen and J. C. Berington), Pergamon, Oxford, 1989, Vol. 5, p. 359

11 Margolina, A. and Wu, S. Polymer 1988, 29, 2170

12 Irwin, G. R. Appl. Mater. Res. 1964, 3, 65

13 McClinttock, F. A. and Irwin, G. R. 'Plasticity Aspects of Fracture Mechanics', ASTM, STP 381, 1965, p. 84

14 Dijkstra, K., ter Laak, J. and Gaymans, R. J. Polymer 1994, 35, 315

15 Dijkstra, K. and ten Bolscher, G. H. J. Mater. Sci. submitted

16 Dijkstra, K. and Gaymans, R. J. J. Mater. Sci. submitted 